Received Date : 16-Jan-2019

Revised Date : 09-Jul-2019

Accepted Date : 16-Aug-2019

\title{
Biochemical and biophysical comparison of human and mouse beta-2 microglobulin reveals the molecular determinants of low amyloid propensity
}

Adnane Achour ${ }^{1 \#}$, Luca Broggini ${ }^{2}$, Xiao Han $^{1}$, Renhua Sun ${ }^{1}$, Carlo Santambrogio ${ }^{3}$, Jeremie Buratto ${ }^{1}$, Cristina Visentin ${ }^{2}$, Alberto Barbiroli ${ }^{4}$, Chiara Maria Giulia De Luca ${ }^{5}$, Pietro Sormanni ${ }^{6}$, Fabio Moda ${ }^{5}$, Alfonso De Simone ${ }^{7}$, Tatyana Sandalova ${ }^{1}$, Rita Grandori ${ }^{3}$, Carlo Camilloni ${ }^{2 \#}$, Stefano Ricagno ${ }^{2 \#}$

${ }^{1}$ Science for Life Laboratory, Department of Medicine Solna, Karolinska Institute, and Division of Infectious Diseases, Karolinska University Hospital, Solna, SE-17176 Stockholm, Sweden;

${ }^{2}$ Dipartimento di Bioscienze, Università degli Studi di Milano, Milan, Italy;

${ }^{3}$ Dipartimento di Biotecnologie e Bioscienze, Università Milano-Bicocca, Milan, Italy;

${ }^{4}$ Dipartimento di Scienze per gli Alimenti, la Nutrizione e l'Ambiente, Università degli Studi di Milano, Milan, Italy;

${ }^{5}$ Fondazione IRCCS Istituto Neurologico Carlo Besta, Divisione di Neurologia 5 - Neuropatologia, 20133 Milano, Italy;

${ }^{6}$ Department of Chemistry, University of Cambridge, CB2 1EW, UK;

${ }^{7}$ Department of Life Sciences, Imperial College London, South Kensington, SW7 2AZ, UK.

Correspondence: Adnane Achour, Science for Life Laboratory, Department of Medicine Solna, Karolinska Institute, and Division of Infectious Diseases, Karolinska University Hospital, Stockholm, Sweden, Tel: (+46) 703951023 E-mail: adnane.achour@ki.se; Carlo Camilloni, Dipartimento di Bioscienze, Università degli Studi di Milano, Milan, Italy, Tel: (+39) 02 50314918, E-mail: carlo.camilloni@unimi.it; Stefano Ricagno, Dipartimento di Bioscienze, Università degli Studi di Milano, Milan, Italy, Tel: (+39) 02 50314914, E-mail: stefano.ricagno@unimi.it.

Running title: Murine beta-2 microglobulin amyloid propensity

Article type : Original Article

Keywords: amyloid, structural biology, protein aggregation, crystal structure, molecular dynamics

Abbreviations: $\beta 2 \mathrm{~m}$, beta- 2 microglobulin; $\mathrm{m} \beta 2 \mathrm{~m}$, murine beta- 2 microglobulin; $\mathrm{h} \beta 2 \mathrm{~m}$, human beta2 microglobulin; wt, wild type; MHC-I, major histocompatibility complex class I; DRA, dialysisrelated amyloidosis; ThT, thioflavin T; TFE, 2,2,2 trifluoroethanol; MS, mass spectrometry; M\&M, metadynamics metainference; $\mathrm{AB}$, AlphaBeta collective variable.

\section{ABSTRACT}

The molecular bases of amyloid aggregation propensity are still poorly understood, especially for proteins that display a stable folded native structure. A prototypic example is human beta-2 microglobulin $(\beta 2 \mathrm{~m})$, which, when accumulated in patients, gives rise to dialysis-related amyloidosis. Interestingly, although the physiologic concentration of $\beta 2 \mathrm{~m}$ in mice is five times higher than that found in human patients, no amyloid deposits are observed in mice. Moreover, murine $\beta 2 \mathrm{~m}$ not only displays a lower amyloid propensity both in vivo and in vitro, but also inhibits the aggregation of human $\beta 2 \mathrm{~m}$ in vitro. Here we compared human and murine $\beta 2 \mathrm{~m}$ for their aggregation propensity, ability to form soluble oligomers, stability, three-dimensional structure and dynamics. Our results indicate that murine $\beta 2 \mathrm{~m}$ low-aggregation propensity is due to two concomitant aspects: the low aggregation propensity of its primary sequence combined with the absence of high-energy amyloidcompetent conformations under native conditions. The identification of the specific properties

This article has been accepted for publication and undergone full peer review but has not been through the copyediting, typesetting, pagination and proofreading process, which may lead to differences between this version and the Version of Record. Please cite this article as doi: 10.1111/febs.15046

This article is protected by copyright. All rights reserved. 
determining the low aggregation propensity of mouse $\beta 2 \mathrm{~m}$ will help delineate the molecular risk factors which cause a folded protein to aggregate.

\section{INTRODUCTION}

The 99-residue-long $\beta 2 \mathrm{~m}$ protein is the invariable subunit, non-covalently bound to the heavy chain in major histocompatibility complex class I molecules (MHC-I). The globular $\beta 2 \mathrm{~m}$ molecule displays a typical immunoglobulin-like fold with seven $\beta$-strands arranged in two $\beta$-sheets, ABDE and CFG, linked by a disulphide bond [1]. The overall stability of MHC-I/peptide complexes depends on the qualities and affinity of the bound antigen [2-5]. When $\beta 2 \mathrm{~m}$ interacts with the MHC-I heavy chain, it is highly stabilised while the unbound $\beta 2 \mathrm{~m}$ monomer may exert its amyloidogenic potential [6]. Indeed, it is well established that human $\beta 2 \mathrm{~m}(\mathrm{~h} \beta 2 \mathrm{~m})$ is an aggregation-prone protein responsible for at least two types of amyloid-related diseases. The aggregation of wild type $\mathrm{h} \beta 2 \mathrm{~m}$ induces DialysisRelated Amyloidosis (DRA) [7]. Conversely, a severe hereditary systemic amyloidosis is linked to the $\mathrm{D} 76 \mathrm{~N}$ variant of $\mathrm{h} \beta 2 \mathrm{~m}$ [8]. Physiologically, $\mathrm{h} \beta 2 \mathrm{~m}$ is degraded in the kidneys. Thus, DRA patients typically suffer from kidney dysfunction with a consequent accumulation of $h \beta 2 \mathrm{~m}$. Over the years, such pathologically high concentration results in aggregation and amyloid deposition in the skeletal joints, bones and muscles, leading to bone fragility and movement impairment [9]. Interestingly, while a $\mathrm{h} \beta 2 \mathrm{~m}$ concentration up to $4.3 \mu \mathrm{M}$ is typical for DRA patients [10], the physiologic concentration of murine $\beta 2 \mathrm{~m}(\mathrm{~m} \beta 2 \mathrm{~m})$ is usually around $22 \mu \mathrm{M}$ but no amyloid aggregation is observed in the mouse [11]. This indicates a much lower amyloidogenic potential for $\mathrm{m} \beta 2 \mathrm{~m}$ compared to $\mathrm{h} \beta 2 \mathrm{~m}$. The picture is however more complex as Zhang et al showed that overexpressed $\mathrm{h} \beta 2 \mathrm{~m}$ in mouse does not aggregate, suggesting that either some molecular elements necessary to aggregation are missing or that the mouse life span is not sufficient for $h \beta 2 \mathrm{~m}$ to successfully aggregate [12]. In vitro, Pashley et al. identified the increased solubility of $\mathrm{m} \beta 2 \mathrm{~m}$ as the main reason for its lower aggregation propensity compared to $\mathrm{h} \beta 2 \mathrm{~m}$ [13]. Intriguingly, Radford and co-workers recently demonstrated that despite both $\mathrm{h} \beta 2 \mathrm{~m}$ and its highly aggregation-prone truncated variant $\triangle \mathrm{N} 6-\mathrm{h} \beta 2 \mathrm{~m}$ can interact with $\mathrm{m} \beta 2 \mathrm{~m}, \mathrm{~m} \beta 2 \mathrm{~m}$ does not aggregate. Moreover, the murine protein is capable to inhibit the aggregation of both $\mathrm{h} \beta 2 \mathrm{~m}$ and $\Delta \mathrm{N} 6-\mathrm{h} \beta 2 \mathrm{~m}[14,15]$.

Altogether, a solid amount of previous work has demonstrated that $\mathrm{h} \beta 2 \mathrm{~m}$ aggregation propensity stems from several specific properties, including the stability of the folded state $[14,16,17]$ as well as the presence of several aggregation prone residues on the surface of $h \beta 2 \mathrm{~m}[18,19]$. Recent publications have also highlighted the crucial role of protein dynamics in determining $h \beta 2 \mathrm{~m}$ aggregation propensity by exposing aggregation prone regions $[18,20]$.

In order to shed further light into how $\mathrm{m} \beta 2 \mathrm{~m}$ is protected from amyloid aggregation and can unexpectedly act as an inhibitor of $\mathrm{h} \beta 2 \mathrm{~m}$ amyloid formation, a mixed structural, biophysical and computational approach was undertaken.

\section{RESULTS}

\section{$m \beta 2 m$ displays lower amyloid propensity compared to $h \beta 2 m$}

It has been previously demonstrated that $\mathrm{m} \beta 2 \mathrm{~m}$ does not display the aggregation propensity typical of $\mathrm{h} \beta 2 \mathrm{~m}[11,13]$. We initiated the present study by testing two different well-established aggregation protocols to confirm these observations. Soluble $\mathrm{h} \beta 2 \mathrm{~m}$ and $\mathrm{m} \beta 2 \mathrm{~m}$ were incubated 100 hours at $37{ }^{\circ} \mathrm{C}$ at $\mathrm{pH} 2.5$ and at $\mathrm{pH} 7.4$ in presence of $20 \% \mathrm{v} / \mathrm{v} 2,2,2$ trifluoroethanol (TFE). Incubations were performed both in absence and presence of seeds prepared from preformed $\mathrm{h} \beta 2 \mathrm{~m}$ fibrils [21]. Our results confirm that $\mathrm{h} \beta 2 \mathrm{~m}$ aggregates abundantly under both these conditions, while $\mathrm{m} \beta 2 \mathrm{~m}$ remains soluble and does not display any sign of aggregation (Fig. 1A-B). A sequence-based analysis of the solubility - and in turn aggregation propensity - of $\mathrm{m} \beta 2 \mathrm{~m}$ or $\mathrm{h} \beta 2 \mathrm{~m}$ using CamSol [22] revealed that the overall aggregation propensity is comparable along the two protein sequences except for the regions corresponding to amino acid residues 60-70 (E strand) and 80-90 (F-G strands). Our analysis

This article is protected by copyright. All rights reserved. 
indicated that these two regions are markedly more aggregation prone in $\mathrm{h} \beta 2 \mathrm{~m}$ than in $\mathrm{m} \beta 2 \mathrm{~m}$ (Fig. 1C).

\section{Under native conditions $m \beta 2 m$ forms less oligomers compared to $h \beta 2 m$}

Native mass-spectrometry (MS) was thereafter employed to assess the oligomerization propensity of $\mathrm{h} \beta 2 \mathrm{~m}$ and $\mathrm{m} \beta 2 \mathrm{~m}$ under non-denaturing conditions. As previously shown, $\mathrm{h} \beta 2 \mathrm{~m}$ displays a pronounced tendency to oligomerize under native conditions [23], with a considerable protein fraction $(\sim 20 \%)$ in oligomeric states of variable stoichiometry (dimer and trimer) (Fig. 2A). Under the same experimental conditions, $\mathrm{m} \beta 2 \mathrm{~m}$ displays a significantly reduced propensity to form oligomers, with only a minor fraction of the population $(\sim 2 \%)$ detectable in the dimeric state and no higher-order species (Fig. 2B). This reduced oligomerization tendency under native-like conditions could be related to the lower aggregation propensity of $\mathrm{m} \beta 2 \mathrm{~m}$ relative to $\mathrm{h} \beta 2 \mathrm{~m}$. The murine D85V variant (see below) presents an oligomeric pattern much more similar to $\mathrm{h} \beta 2 \mathrm{~m}$ (Figure 2D). Furthermore, the $\mathrm{m} \beta 2 \mathrm{~m}$ monomer is characterized by a bimodal charge-state distribution (Fig. 2B), suggesting the existence of a minor, at least partially unfolded component, which is not observed in $\mathrm{h} \beta 2 \mathrm{~m}$. These results indicate a lower conformational stability of the $\mathrm{m} \beta 2 \mathrm{~m}$ variant. To rule out the effects of accidental variability in the experimental conditions, an equimolar mixture of the two $\beta 2 \mathrm{~m}$ variants was analyzed, confirming the presence of the peaks for the unfolded component only for $\mathrm{m} \beta 2 \mathrm{~m}$ (Fig. $2 \mathrm{C}$ ). Crucially the spectrum of the mixture also revealed that the oligomerization pattern of $h \beta 2 \mathrm{~m}$ is affected by the presence of $\mathrm{m} \beta 2 \mathrm{~m}$. $\beta 2 \mathrm{~m}$ heterodimers are formed, but a significant decrease in the amount of $\mathrm{h} \beta 2 \mathrm{~m}$ oligomers is also observed. The ability of $\mathrm{m} \beta 2 \mathrm{~m}$ to interact with $\mathrm{h} \beta 2 \mathrm{~m}$ and to reduce $\mathrm{h} \beta 2 \mathrm{~m}$ oligomerization propensity could be related to the previously reported inhibitory effect of $\mathrm{m} \beta 2 \mathrm{~m}$ on $\mathrm{h} \beta 2 \mathrm{~m}$ aggregation $[14,15]$.

\section{The crystal structure of monomeric $m \beta 2 m$ reveals localized conformational changes compared to $h \beta 2 m$}

In order to better understand the molecular interactions occurring in the oligomers, the crystal structure of $\mathrm{m} \beta 2 \mathrm{~m}$ was determined to $1.92 \AA$ resolution, providing an electron density of excellent quality (Table 1). As expected, the three-dimensional structure of $\mathrm{m} \beta 2 \mathrm{~m}$ takes a typical $\beta$-sandwich fold (Fig. 3A). Interestingly, comparison of the crystal structures of $\mathrm{m} \beta 2 \mathrm{~m}$ and $\mathrm{h} \beta 2 \mathrm{~m}$ reveals that $\mathrm{m} \beta 2 \mathrm{~m}$ resembles more closely to $\mathrm{h} \beta 2 \mathrm{~m}$ or $\mathrm{m} \beta 2 \mathrm{~m}$ when bound to MHC-I [24, 25], compared to soluble monomeric $\mathrm{h} \beta 2 \mathrm{~m}$ [26] (Fig. 3A-C). In particular, the three-dimensional structure of the monomeric $\mathrm{m} \beta 2 \mathrm{~m}$ reveals that the $\mathrm{AB}$ loop, connecting the $\mathrm{A}$ and $\mathrm{B}$ strands, takes the same closed conformation as found in $\mathrm{h} \beta 2 \mathrm{~m}$ when bound to MHC-I (Fig. 3B-C). Furthermore, the D-strand is bulged at residue 53 in both monomeric $\mathrm{m} \beta 2 \mathrm{~m}$ and MHC-I-bound $\mathrm{h} \beta 2 \mathrm{~m}$ compared to monomeric $\mathrm{h} \beta 2 \mathrm{~m}$ (Fig. 3) [17, 21, 27, 28]. This is reflected by the RMSD values of $0.87 \AA$ A over $99 \mathrm{C} \alpha$ and of $1.13 \AA$ over $90 \mathrm{C} \alpha$ following the superposition of unbound $\mathrm{m} \beta 2 \mathrm{~m}$ onto MHC-I-bound $\mathrm{h} \beta 2 \mathrm{~m}$ or monomeric $\mathrm{h} \beta 2 \mathrm{~m}$, respectively. Most importantly, several regions considered as highly relevant for $\mathrm{h} \beta 2 \mathrm{~m}$ aggregation present analogous conformational arrangements in monomeric $\mathrm{m} \beta 2 \mathrm{~m}$. First, Pro32 is in cis conformation. This isomerisation from cis to trans is considered as a fundamental step towards the formation of the aggregation prone intermediate [29]. Furthermore, the aromatic residues (Y10, Y26, F56, W60, F62, Y63), involved in Thioflavin T (ThT) binding [30] and crucial for $\mathrm{h} \beta 2 \mathrm{~m}$ amyloid aggregation [19], display very similar structural conformations in both structures. Finally, a Ramachandran plot analysis of $\mathrm{m} \beta 2 \mathrm{~m}$ reveals that the strained geometry of the DE-loop is perfectly comparable to the one observed in monomeric $\mathrm{h} \beta 2 \mathrm{~m}$. This loop is directly involved in the destabilisation of the $\mathrm{h} \beta 2 \mathrm{~m}$ fold [23, 31]. In summary, the monomeric structure of $\mathrm{m} \beta 2 \mathrm{~m}$ does not display any major conformational changes in regions known to be relevant for amyloid formation compared to $\mathrm{h} \beta 2 \mathrm{~m}$.

This article is protected by copyright. All rights reserved. 


\section{m $\beta 2 m$ may form $D D$ dimers}

To date, several works have proposed that a head to head interaction named DD strand interface, formed between $\mathrm{h} \beta 2 \mathrm{~m}$ molecules, may be the first intermolecular interaction along the $\beta 2 \mathrm{~m}$ aggregation pathway $[15,30,32,33]$. This DD interface involves several $\beta 2 \mathrm{~m}$ regions, which are all relevant for aggregation including the D-strand as well as the BC and DE loops [32]. Using the crystal structures of monomeric $\mathrm{m} \beta 2 \mathrm{~m}$ and $\mathrm{h} \beta 2 \mathrm{~m}$, hypothetical molecular models of murine and heterodimeric murine-human DD complexes were created and analysed (Fig. 3D-F). No steric clashes were observed in these molecular models, suggesting that both $\mathrm{m} \beta 2 \mathrm{~m}$ and $\mathrm{h} \beta 2 \mathrm{~m}$ are fully compatible with the formation of a DD interface. Indeed, mixed dimers were also formed (Fig. 2). Moreover, a PISA analysis indicated that the dimer formation between two $\mathrm{h} \beta 2 \mathrm{~m}$ molecules seems to be more energetically favourable compared to the murine dimer (interface area and energy gain on complex formation corresponded $225 \AA /-1.1 \mathrm{kcal} / \mathrm{mol}$ and $171 \AA /-0.2 \mathrm{kcal} / \mathrm{mol}$ for dimeric $\mathrm{h} \beta 2 \mathrm{~m}$ and $\mathrm{m} \beta 2 \mathrm{~m}$, respectively). This result well correlates with the observation that, under native conditions, $\mathrm{m} \beta 2 \mathrm{~m}$ forms significantly less dimers compared to $\mathrm{h} \beta 2 \mathrm{~m}$ (Fig. 2).

\section{$m \beta 2 m$ displays lower stability compared to $h \beta 2 m$}

Since $\beta 2 \mathrm{~m}$ aggregation propensity correlates with thermodynamic stability of the native state [31], the fold stability of the two $\beta 2 \mathrm{~m}$ orthologs was assessed by temperature ramps (temperature slope 50 ${ }^{\circ} \mathrm{C} /$ hour) monitored by Far-UV circular dichroism. Thermal denaturation demonstrated that $\mathrm{m} \beta 2 \mathrm{~m}$ unfolds at lower temperature compared to $\mathrm{h} \beta 2 \mathrm{~m}$ (Tm values of $58.9 \pm 0.8^{\circ} \mathrm{C}$ and $63.6 \pm 1.0^{\circ} \mathrm{C}$ for $\mathrm{m} \beta 2 \mathrm{~m}$ and $\mathrm{h} \beta 2 \mathrm{~m}$, respectively) (Fig. 4A). Unexpectedly, although significantly less amyloidogenic, $\mathrm{m} \beta 2 \mathrm{~m}$ is also less stable than $\mathrm{h} \beta 2 \mathrm{~m}$.

The structural dynamics of the two protein variants were further investigated by analysis of the reduction kinetics of the internal disulphide bridge formed between the cysteine residues $\mathrm{C} 25$ and C80. This process is very slow under non-denaturing conditions for $\mathrm{h} \beta 2 \mathrm{~m}$, due to the buried structural environment of the disulphide bridge [23, 34]. Monomeric $\mathrm{h} \beta 2 \mathrm{~m}$ and $\mathrm{m} \beta 2 \mathrm{~m}$ were mixed and incubated under native but strongly reducing conditions. Aliquots were collected at different time points and free thiols were alkylated by allyl-bromide. The resulting samples were purified and analyzed by denaturing MS (Fig. 4B). After 30 minutes, both variants remained completely oxidized. The presence of species with reduced/alkylated cysteine residues became evident only after one-hour incubation, when $\mathrm{m} \beta 2 \mathrm{~m}$ became highly reduced ( $60 \%$, estimated by the sum of single- and doublealkylated species), while $\mathrm{h} \beta 2 \mathrm{~m}$ remained prevalently in the oxidized form $(\sim 80 \%)$. After three hours of incubation, approximately $90 \%$ and $70 \%$ of $\mathrm{m} \beta 2 \mathrm{~m}$ and $\mathrm{h} \beta 2 \mathrm{~m}$ were reduced, respectively. Taken together, these results suggest a higher accessibility of the disulphide bridge within $\mathrm{m} \beta 2 \mathrm{~m}$ compared to $\mathrm{h} \beta 2 \mathrm{~m}$ under these conditions.

\section{$m \beta 2 m$ ensemble does not show high-energy states and displays a lower aggregation propensity}

In order to characterise the conformational properties of $\mathrm{m} \beta 2 \mathrm{~m}$ and $\mathrm{h} \beta 2 \mathrm{~m}$, we first measured and assigned backbone chemical shifts for $\mathrm{m} \beta 2 \mathrm{~m}$ as previously described (Fig. 3G) [35]. Experimental NMR data were already available in the literature for $\mathrm{h} \beta 2 \mathrm{~m}$ [36]. We thereafter employed NMR chemical shifts as restraints in Metadynamics Metainference (M\&M) simulations [37]. The resulting M\&M simulations were carried out until convergence (Fig. 5) with a statistical error on the resulting conformational free energies of less than $1 \mathrm{~kJ} / \mathrm{mol}$. The resulting structural ensembles was then analyzed as a function of the side-chain rotamer distribution (AlphaBeta collective variable; $A B$ ) and the antiparallel $\beta$-structure content (AntiBetaRMSD CV; anti- $\beta$ ) (Fig. 6A). The resulting free energy surfaces are then comparable with those formerly obtained for other $\beta 2 \mathrm{~m}$ variants $[18,20]$. The Free Energy Surface (FES) for $h \beta 2 m$ and $m \beta 2 m$ display remarkable differences. $h \beta 2 m$ is characterized by a global minimum and by the presence of a high-energy low populated state. The global minimum (anti- $\beta$ variable between 19 and 22 , corresponding to a beta content between 38 and $44 \%$ ) is structurally similar to the crystal structure (average RMSD of $1.5 \AA$ ), while the high-energy state (anti- $\beta$ between 17 and 18 corresponding to a beta content between 34 and 36\%) is slightly more disordered (average RMSD of $3 \AA$ ). The free energy for $m \beta 2 m$ displays a single minimum with slightly higher average beta content as well as larger fluctuations (anti- $\beta$ between 19 and 25

This article is protected by copyright. All rights reserved. 
corresponding to a beta content between 34 and $36 \%$, and an average RMSD with respect to the crystal of $\mathrm{m} \beta 2 \mathrm{~m}$ of $1.8 \AA$ ) compared to $\mathrm{h} \beta 2 \mathrm{~m}$. Intriguingly, the FES does not reveal the presence of any high-energy state (Fig. 6A). Notably, in a recent work simulations and experiments indicate the presence of a high energy state in both $\mathrm{h} \beta 2 \mathrm{~m}$ and the $\mathrm{D} 76 \mathrm{~N} \mathrm{~h} \beta 2 \mathrm{~m}$ variant characterized by loss of secondary structure [20].

The $\mathrm{h} \beta 2 \mathrm{~m}$ and $\mathrm{m} \beta 2 \mathrm{~m}$ conformational ensembles were subsequently used in combination with the program CamSol to generate a per-residue analysis of the aggregation propensity under native conditions (Fig. 6B). Remarkably, the most relevant difference in the obtained aggregation propensity profiles was observed for residue 85 , a valine in $\mathrm{h} \beta 2 \mathrm{~m}$ and an aspartic acid in $\mathrm{m} \beta 2 \mathrm{~m}$. Interestingly, this position has already been determined as crucial for $\mathrm{h} \beta 2 \mathrm{~m}$ aggregation. Indeed, the rationally designed V85E $\mathrm{h} \beta 2 \mathrm{~m}$ variant displays significantly less aggregation propensity compared to $\mathrm{h} \beta 2 \mathrm{~m}$ with a comparable fold stability [18]. To better distinguish the role of structure and dynamics in determining the aggregation properties of $\beta 2 \mathrm{~m}$, we also compared the profiles averaged over the ensemble with those calculated from the crystal structures (Fig. 6B). Interestingly, in $h \beta 2 \mathrm{~m}$ the dynamics increase the surface aggregation propensity, while we observe the opposite behaviour for $\mathrm{m} \beta 2 \mathrm{~m}$. In fact, the profile calculated over the ensemble for $\mathrm{m} \beta 2 \mathrm{~m}$ displays much less aggregation prone regions compared to the crystal structure.

Thus, the comparison of the M\&M conformational ensembles indicates that while the aspartic acid $\mathrm{D} 85$ in $\mathrm{m} \beta 2 \mathrm{~m}$ may be critical for its remarkably lower aggregation propensity, the relative dynamics of the two proteins also contribute to either increased (for $\mathrm{h} \beta 2 \mathrm{~m}$ ) or decreased (for $\mathrm{m} \beta 2 \mathrm{~m}$ ) overall aggregation propensity.

\section{The presence of $V 85$ increases the aggregation propensity of $m \beta 2 m$ in vitro}

All previous studies on $\mathrm{m} \beta 2 \mathrm{~m}$ aggregation propensity have focused on the D85 $\mathrm{m} \beta 2 \mathrm{~m}$ variant (herein named $\mathrm{m} \beta 2 \mathrm{~m}$ ), but in contrast to $\mathrm{h} \beta 2 \mathrm{~m}$, several variants of $\mathrm{m} \beta 2 \mathrm{~m}$ have been identified. Among these a valine residue at position 85 has been previously reported [38, 39]. We therefore mutated the aspartate residue at position 85 to a valine and characterized the $D 85 \mathrm{~V} \mathrm{~m} \beta 2 \mathrm{~m}$ variant $(\mathrm{V} 85 \mathrm{~m} \beta 2 \mathrm{~m})$ in order to verify the importance of this position in determining $\mathrm{m} \beta 2 \mathrm{~m}$ aggregation propensity. The stability of V85 $\mathrm{m} \beta 2 \mathrm{~m}$ was evaluated by monitoring its thermal denaturation by far-UV CD measurements. Our results revealed that the Tm value for V85 $\mathrm{m} \beta 2 \mathrm{~m}$ is slightly higher compared to $\mathrm{m} \beta 2 \mathrm{~m}\left(61.4 \pm 0.8{ }^{\circ} \mathrm{C}\right.$ and $58.9 \pm 0.8{ }^{\circ} \mathrm{C}$, respectively) (Fig. 7A). Thus, the aspartic acid to valine substitution at position 85 does not alter significantly the overall fold stability of the mutated variant compared to $\mathrm{m} \beta 2 \mathrm{~m}$. On the other hand, $V 85 \mathrm{~m} \beta 2 \mathrm{~m}$ has a higher propensity to oligomerize relative to $\mathrm{m} \beta 2 \mathrm{~m}$, resulting in the formation of a dimeric population similar to the one detected for $\mathrm{h} \beta 2 \mathrm{~m}$ (Fig. 2D). We then assessed the aggregation propensity of V85 $\mathrm{m} \beta 2 \mathrm{~m}$ as described above. Our results demonstrate that, at $\mathrm{pH} 2.5$, V85 $\mathrm{m} \beta 2 \mathrm{~m}$ aggregates considerably compared to $\mathrm{m} \beta 2 \mathrm{~m}$ in the presence of seeds of $\mathrm{h} \beta 2 \mathrm{~m}$ (Fig. 7B). Furthermore, seeds of V85 m $\beta 2 \mathrm{~m}$ fibrils also successfully triggered $\mathrm{h} \beta 2 \mathrm{~m}$ aggregation but not $\mathrm{m} \beta 2 \mathrm{~m}$ aggregation. Finally, the fibrillar nature of V85 $\mathrm{m} \beta 2 \mathrm{~m}$ aggregates was also verified using transmission electron microscopy (Fig. 7C). Altogether, our results demonstrate that the V85 mutation facilitates $\mathrm{m} \beta 2 \mathrm{~m}$ aggregation, further supporting the key role of this position.

\section{DISCUSSION}

$\beta 2 \mathrm{~m}$ has been studied as a model for amyloid aggregation for decades [40]. This protein is of particular interest given that its fold is highly stable, which is a somehow counterintuitive property for an amyloidogenic protein. Indeed, only abnormally high $\mathrm{h} \beta 2 \mathrm{~m}$ concentration over several years triggers aggregation leading to DRA. Interestingly $\mathrm{m} \beta 2 \mathrm{~m}$ is not amyloidogenic in vivo or in vitro [11] and mixed oligomers of $\mathrm{m} \beta 2 \mathrm{~m}$ with $\mathrm{h} \beta 2 \mathrm{~m}$ seeds inhibit the aggregation capacity of $\mathrm{h} \beta 2 \mathrm{~m}[11,15]$. It is well established that $\mathrm{m} \beta 2 \mathrm{~m}$ has a higher saturation concentration compared to $\mathrm{h} \beta 2 \mathrm{~m}$, resulting in a lower aggregation propensity [13]: However, the results presented within this study suggest in our opinion a more complex picture.

This article is protected by copyright. All rights reserved. 
We have previously reported that $\mathrm{h} \beta 2 \mathrm{~m}$ displays a marked tendency to form soluble oligomers under native conditions [23]. Conversely, we here demonstrate that $\mathrm{m} \beta 2 \mathrm{~m}$ displays a very limited tendency to oligomerize, forming relatively small amounts of only dimers. Remarkably, $\mathrm{h} \beta 2 \mathrm{~m}$ oligomerisation is significantly inhibited in presence of $\mathrm{m} \beta 2 \mathrm{~m}$, even though heterodimers are detectable in $\mathrm{m} \beta 2 \mathrm{~m}$ $\mathrm{h} \beta 2 \mathrm{~m}$ mixtures. This suggests that the decreased oligomerisation could be mediated by $\mathrm{h} \beta 2 \mathrm{~m}-\mathrm{m} \beta 2 \mathrm{~m}$ protein-protein interactions. (Fig. 2). Moreover, based on the crystal structure of $\mathrm{m} \beta 2 \mathrm{~m}$, a hypothetical molecular model of a DD-m $\beta 2 \mathrm{~m}$ dimer was designed, indicating no major structural steric clashes upon dimer formation. Interestingly, the calculated energy gain upon dimer $\mathrm{m} \beta 2 \mathrm{~m}$ formation was significantly reduced compared to $\mathrm{h} \beta 2 \mathrm{~m}$ dimer models, suggesting a less optimized interface in $\mathrm{m} \beta 2 \mathrm{~m}$ dimers compared to $\mathrm{h} \beta 2 \mathrm{~m}$ dimers. This observation may explain several previous results. Karamanos et al observed that although the $\mathrm{h} \beta 2 \mathrm{~m} / \mathrm{h} \beta 2 \mathrm{~m}$ homodimer and the $\mathrm{m} \beta 2 \mathrm{~m} / \mathrm{h} \beta 2 \mathrm{~m}$ heterodimer may have comparable interaction interfaces, the formation of the $\mathrm{h} \beta 2 \mathrm{~m} / \mathrm{h} \beta 2 \mathrm{~m}$ homodimer is instrumental to amyloid formation while $\mathrm{m} \beta 2 \mathrm{~m} / \mathrm{h} \beta 2 \mathrm{~m}$ heterodimerization results in an inhibitory complex, impairing amyloid formation [15]. It is thus possible that $\mathrm{m} \beta 2 \mathrm{~m}$ competes with the formation of $\mathrm{h} \beta 2 \mathrm{~m}$ homodimers and either kinetically or thermodynamically impairs the formation of higher order oligomers. Thus altogether, our results suggest that sub-optimal DD interface formed within $\mathrm{m} \beta 2 \mathrm{~m} / \mathrm{m} \beta 2 \mathrm{~m}$ homodimers may protect $\mathrm{m} \beta 2 \mathrm{~m}$ from inducing amyloid aggregation. Similarly, the DD interface formed in $\mathrm{m} \beta 2 \mathrm{~m} / \mathrm{h} \beta 2 \mathrm{~m}$ heterodimers may also perturb the appropriate formation of $\mathrm{h} \beta 2 \mathrm{~m}$ oligomers.

Our results demonstrate that specific segments of $m \beta 2 \mathrm{~m}$ sequence (residues 60-70 and 80-90), and to a lesser extent the dynamics, play also crucial roles in determining its low aggregation propensity. Indeed, the analyses of the primary sequence and of the computed aggregation propensity of the conformational ensembles indicate that residue D85 plays a key role in the significant reduction of $\mathrm{m} \beta 2 \mathrm{~m}$ aggregation propensity compared to $\mathrm{h} \beta 2 \mathrm{~m}$. Accordingly, the V85 $\mathrm{m} \beta 2 \mathrm{~m}$ variant presents a oligomerization pattern similar to human wild type and displays an amyloidogenicity comparable to $\mathrm{h} \beta 2 \mathrm{~m}$ under denaturing conditions, while $\mathrm{m} \beta 2 \mathrm{~m}$ is mainly monomeric under non-denaturing conditions, and remains soluble under the same amyloidogenic conditions as previously reported [13]. This is well in line with data showing that residues 83 and 85 are crucial in determining $\mathrm{h} \beta 2 \mathrm{~m}$ aggregation [18].

It thus remains to be determined if the V85 $\mathrm{m} \beta 2 \mathrm{~m}$ variant would display the same amyloidogenicity as $\mathrm{h} \beta 2 \mathrm{~m}$ in vivo or if the low oligomerisation tendency observed for $\mathrm{m} \beta 2 \mathrm{~m}$ is sufficient to hinder aggregation. Finally, high-energy, partially misfolded, states have been suggested to play a role in protein aggregation by providing aggregation prone structures [29, 41, 42]. In a recent work on the $\mathrm{D} 76 \mathrm{~N} \mathrm{~h} \beta 2 \mathrm{~m}$ mutant we observed that the aggregation propensity of the high-energy state populated by $\mathrm{D} 76 \mathrm{~N} \mathrm{~h} \beta 2 \mathrm{~m}$ is more pronounced with respect to that of the high-energy state formed by $\mathrm{h} \beta 2 \mathrm{~m}$ and may explain the stronger aggregation propensity of the D76N variant [20]. Consequently, the lack of such state for $\mathrm{m} \beta 2 \mathrm{~m}$ is compatible with the different tendencies of $\mathrm{h} \beta 2 \mathrm{~m}$ and $\mathrm{m} \beta 2 \mathrm{~m}$ to oligomerize and for amyloid fibrils.

The results presented within this study shed additional light on the molecular bases underlying the different aggregation propensities of $\beta 2 \mathrm{~m}$ in human and mouse, and provide new possible mechanisms for $\mathrm{m} \beta 2 \mathrm{~m}$ inhibition of $\mathrm{h} \beta 2 \mathrm{~m}$ aggregation. The possibility of blocking pathologic protein misfolding by using a non-aggregative $\mathrm{m} \beta 2 \mathrm{~m}$ variant may be a tantalizing and generalizable strategy to address amyloid aggregation.

\section{Materials and Methods}

Preparation of the human $\beta 2 m$

The $\mathrm{h} \beta 2 \mathrm{~m}$ was expressed and purified as previously reported in [43].

This article is protected by copyright. All rights reserved. 


\section{Preparation of the murine $\beta 2 m$}

The $\mathrm{m} \beta 2 \mathrm{~m}$ sequence encoding amino acids $1-99$ was cloned in a pET- $8 \mathrm{c}$ plasmid. D to $\mathrm{V}$ mutagenesis of $\mathrm{m} \beta 2 \mathrm{~m}$ was performed using the QuikChange Lightning site-directed mutagenesis kit supplied by Agilent (Santa Clara, CA) according to manufacturer instructions. The following primers were used: 5'-GCAGAGTTAAGCATGTCAGTATGGCCGAGCC-3' and GGCTCGGCCATACTGACATGCTTAACTCTGC-3'.

The expression vectors were transformed into BL21(DE3)pLysS (Novagen). The protein production was IPTG induced and the product was purified as inclusion bodies as for $\mathrm{h} \beta 2 \mathrm{~m}$. The concentration of the final product was determined spectrophotometrically and purity of the product was assessed by SDS-PAGE under denaturing conditions. Refolding was performed by dialysis at $4{ }^{\circ} \mathrm{C}$ against $20 \mathrm{mM}$ Tris $\mathrm{HCl} \mathrm{pH} \mathrm{7.5.} \mathrm{After} 24 \mathrm{~h}$, the refolding mixture was concentrated using Amicon concentration devices. Refolded $\beta 2 \mathrm{~m}$ was purified and buffer exchanged into $20 \mathrm{mM}$ Tris $\mathrm{HCl} \mathrm{pH} 7.0$ by FPLC using Superdex 75 gel filtration (Pharmacia).

\section{Aggregation assays}

Three independent aggregation tests for $\mathrm{h} \beta 2 \mathrm{~m}, \mathrm{~m} \beta 2 \mathrm{~m}$ and the $\mathrm{V} 85 \mathrm{~m} \beta 2 \mathrm{~m}$ variant were performed in triplicate using black, clear-bottom, 96-well microplates, the protein concentration of $100 \mu \mathrm{M}$ was used in all experiments. Plates were incubated in a FLUOstar OPTIMA reader (BMG Labtech, Germany) at $37{ }^{\circ} \mathrm{C}$, over a period of $100 \mathrm{~h}$ with intermittent cycles of shaking (1 min, $300 \mathrm{rpm}$, double-orbital) and rest $(30 \mathrm{~min})$. The ThT fluorescence intensity of the aggregates, expressed as arbitrary units (AU), was taken every 30 min using $450 \pm 10 \mathrm{~nm}$ (excitation) and $480 \pm 10 \mathrm{~nm}$ (emission) wavelength, with a bottom read and a gain of 1000. All reaction mixes were freshly prepared and optimized for self-assembly or seeding experiments under two different conditions: 50 $\mathrm{mM}$ phosphate buffer and $100 \mathrm{mM} \mathrm{NaCl}, \mathrm{pH} \mathrm{7.4}$, in the presence of $20 \% \mathrm{v} / \mathrm{v}$ TFE [44]; $50 \mathrm{mM}$ sodium citrate and $100 \mathrm{mM} \mathrm{NaCl}, \mathrm{pH} 2.5$ [45].

\section{Transmission electron microscopy analysis}

Morphological analysis of V85 $\mathrm{m} \beta 2 \mathrm{~m}$ aggregates were carried out adsorbing $10 \mu \mathrm{L}$ of sample onto carbon-coated 200-mesh grids and staining with UAR replacement (negative staining), using a FEI Tecnai Spirit transmission electron microscope $(120 \mathrm{kV})$ equipped with an Olimpus Soft imaging solutions Megaview camera. Images were taken at $18500 \mathrm{X}$ magnification.

\section{Mass spectrometry}

ESI-MS spectra under non-denaturing conditions (50 mM ammonium acetate, $\mathrm{pH} 7)$ were acquired by direct injection on a Orbitrap Fusion instrument (ThermoFisher Scientific, Waltham, MA, USA). The main instrumental parameters were: ion-spray voltage, $3.1 \mathrm{kV}$; source dissociation, $55 \mathrm{~V}$; ion transfer tube temperature, $225^{\circ} \mathrm{C}$; flow rate $2 \mu \mathrm{l} / \mathrm{min}$. Spectra were averaged over 2-minute acquisition.

Disulphide bridge reduction kinetics: mixtures of $25 \mu \mathrm{M} \mathrm{h} \beta 2 \mathrm{~m}$ and $25 \mu \mathrm{M} \mathrm{m} \beta 2 \mathrm{~m}$ were incubated at $37{ }^{\circ} \mathrm{C}$ in $50 \mathrm{mM}$ ammonium carbonate, $100 \mathrm{mM}$ DTT, $\mathrm{pH} 8$, to reduce disulphide bridges. At different incubation times, $10 \mu \mathrm{L}$ aliquots were taken and diluted in $90 \mu \mathrm{L}$ of $20 \%$ cold trichloroacetic acid, vortexed and incubated $30 \mathrm{~min}$ at $4{ }^{\circ} \mathrm{C}$. Then, the sample was centrifuged at $14000 \mathrm{rpm}, 4{ }^{\circ} \mathrm{C}$ for $30 \mathrm{~min}$, and the resulting pellet washed with cold acetone. After lyophilization in a Speed Vac system (Analitica De Mori, Milan, IT), the sample was resuspended in $20 \mu \mathrm{L}$ of $50 \mathrm{mM}$ ammonium carbonate, $\mathrm{pH} 8,130 \mathrm{mM}$ allyl bromide and incubated $1 \mathrm{~h}$ at room temperature for thiol alkylation. Finally, the sample was buffer-exchanged by C18 ZipTips (Merck Millipore, Burlington, MA, USA), with elution by $50 \%$ acetonitrile, $1 \%$ formic acid followed by direct injection into the mass spectrometer. Each of the above experiments was repeated at least three times using different protein batches.

This article is protected by copyright. All rights reserved. 
Crystallisation and structure determination

Crystallization experiments were performed at $293 \mathrm{~K}$ using a hanging drop vapour diffusion method with $6 \mu \mathrm{l}$ of $\mathrm{m} \beta 2 \mathrm{~m}(4 \mathrm{mg} / \mathrm{ml}$ in $20 \mathrm{mM}$ Tris $\mathrm{HCl}, \mathrm{pH} 7.5)$ mixed with $2 \mu \mathrm{l}$ of the reservoir solution and equilibrated against $1 \mathrm{ml}$ of the reservoir solution. The best crystals were obtained in 34\% PEG 8000 w/v, $100 \mathrm{mM}$ Tris HCl, pH 8.0 and in 40\% PEG $6000 \mathrm{w} / \mathrm{v}, 100 \mathrm{mM}$ Tris $\mathrm{HCl}, \mathrm{pH} \mathrm{8.0.} \mathrm{The} \mathrm{crystal}$ was cryo-protected by addition of 34\% PEG $400 \mathrm{w} / \mathrm{v}$. Data were collected at BL711 beam line, MAX Laboratory, Lund the 6/9/1999 $(\lambda=1.018 \AA)$ and were processed and scaled with DENZO and SCALEPACK [46]. The crystal diffracted up to $1.92 \AA$, it belongs to the space group P $22_{1} 2_{1}$ with unit cell dimensions of $36.24 \AA, 47.60 \AA, 64.94 \AA$. The data collection statistics are shown in Table 1 .

The structure of $m \beta 2 \mathrm{~m}$ was solved by molecular replacement using AMoRe [47], $\mathrm{m} \beta 2 \mathrm{~m}$ from the murine MHC-I complex H-2Dd, (PDB code 1BII) was used as an initial model. One subunits of $\mathrm{m} \beta 2 \mathrm{~m}$ was found in the asymmetric unit, crystals display a $51 \%$ solvent content. Refinement was carried with X-PLOR [48] applying strict non-crystallographic symmetry. Last step of refinement was performed in Refmac5 [49]. Statistics for the final model are shown in Table 1.

NMR experiments.

NMR measurements were performed on ${ }^{13} \mathrm{C},{ }^{15} \mathrm{~N}$ labelled $\mathrm{m} \beta 2 \mathrm{~m}$ samples at a concentration of 200 $\mu \mathrm{M}$. Assignment of the backbone resonances was performed by a combination of ${ }^{1} \mathrm{H}-{ }^{15} \mathrm{~N}$ HSQC, $\mathrm{CBCA}(\mathrm{CO}) \mathrm{NH}, \mathrm{HNCACB}, \mathrm{HNCO}$ and $\mathrm{HN}(\mathrm{CA}) \mathrm{CO}$ spectra, collectively providing chemical shifts for ${ }^{13} \mathrm{C} \alpha,{ }^{13} \mathrm{C} \beta,{ }^{1} \mathrm{HN},{ }^{13} \mathrm{CO}$ and ${ }^{15} \mathrm{~N}$ atoms [35].

NMR was performed at $25^{\circ} \mathrm{C}$ using a Bruker AVANCE spectrometer operating at proton frequency of $700 \mathrm{MHz}$, equipped with a triple resonance cryoprobe. NMR data were processed using NMRPipe [50] and analysed using Sparky [51]. Data were processed using the MARS programme [52].

\section{Ensembles determination}

The simulations were carried out using GROMACS [53] and PLUMED [54] with the ISDB module [55]. The system was described using the Amber03W force field [56] in explicit TIP4P05 water [57] at $298 \mathrm{~K}$. The starting conformations were taken from the $2 \mathrm{YXF}$ and the here reported X-ray structure for the $\mathrm{h} \beta 2 \mathrm{~m}$ and $\mathrm{m} \beta 2 \mathrm{~m}$, respectively. The structures were protonated and solvated with $\sim 8200$ water molecules in a dodecahedron box of $\sim 260 \mathrm{~nm}^{3}$ of volume. The M\&M protocol was applied using chemical shifts and a global outlier model for the noise as previously described [37, 58]. Ten replicas of the system were simulated in parallel with a restraint applied on the weighted average value of the back-calculated NMR chemical shifts with a force constant determined on the fly by M\&M [59].

All replicas were biased by Parallel Bias Metadynamics [60] along the following four CVs: the antiparallel beta content (the "anti- $\beta$ " CV), the AlphaBeta CV defined over all the chi- 1 angles for the hydrophobic side-chains (the "AB" $\mathrm{CV}$ ), the AlphaBeta CV defined over all the chi-1 angles for the surface exposed side-chains (the "ABsurf" CV), and the AlphaBeta CV defined over all the phi and psi backbone dihedral angles of the protein (the "bbAB" CV). Definition of the CVs are available in the PLUMED manual. Gaussians deposition was performed with $\sigma$ values automatically determined by averaging the $C V$ fluctuations over 2000 steps and setting a minimum value of $0.1,0.12,0.12$, and 0.12 , for anti- $\beta, A B, A B$ surf, and bbAB, respectively [61]; an initial energy deposition rate of 2.5 $\mathrm{kJ} / \mathrm{mol} / \mathrm{ps}$ and a bias-factor of 20 . Furthermore, in order to limit the extent of accessible space along each collective variable and correctly treat the problem of the borders, intervals were set to 12-30, 10-40, $0-33$, and 10-42 for the four CVs, respectively. Each replica has been run for a nominal time of $400 \mathrm{~ns}$.

The sampling of the 10 replicas was combined using a simple reweighting scheme based on the final metadynamics bias $B$ where the weight $w$ of a conformation $X$ is given by $w=\exp \left(+B(X) / k_{B} T\right)$, with $k_{B}$ the Boltzmann constant and $T$ the temperature, consistently with the quasi static behaviour at convergence of well-tempered metadynamics [61]. The convergence of the simulations by block analysis, including error estimates, is shown in Fig. 5. All the data and PLUMED input files required to reproduce the results reported in this paper are available on PLUMED-NEST (www.plumednest.org), the public repository of the PLUMED consortium as plumID:19.038 [62]. Of notice the free

This article is protected by copyright. All rights reserved. 
energy obtained for $\mathrm{h} \beta 2 \mathrm{~m}$ resembles that previously determined by replica-averaged metadynamics simulations on a slightly different sequence $[18,63]$. The main differences being the lack of a more 'crystal'-like high-energy state and the presence of a slightly more disordered, high-energy, state. This latter was not sampled in a former work [18] because the sampling was not allowed in that region, but was more recently observed by solid state NMR and replica-averaged metadynamics simulations [20].

\section{Circular dichroism}

Thermal stability experiments were performed in triplicate using three independent batches of protein and were monitored in the far-UV region using a J-810 spectropolarimeter (JASCO Corp., Tokyo, Japan) equipped with a Peltier system for temperature control. The protein concentration was 0.1 $\mathrm{mg} / \mathrm{mL}$ in $50 \mathrm{mM}$ sodium phosphate $\mathrm{pH}$ 7.4. The temperature ramps were carried out from 20 to 95 ${ }^{\circ} \mathrm{C}$ (temperature slope $50{ }^{\circ} \mathrm{C} /$ hour) in a $0.1 \mathrm{~cm}$ path length cuvette and monitored at $202 \mathrm{~nm}$ wavelength. Tm was calculated as the first-derivative minimum of the traces. Spectra before and after unfolding ramp were recorded $(260-190 \mathrm{~nm})$. All three $\beta 2 \mathrm{~m}$ variants considered in this work display an irreversible unfolding under the tested conditions.

\section{Accession number}

Atomic coordinates and structure factors for $\mathrm{m} \beta 2 \mathrm{~m}$ have been deposited at the Protein Data Bank, with accession code 6I8C.

\section{REFERENCES}

1. Bjorkman, P. J., Saper, M. A., Samraoui, B., Bennett, W. S., Strominger, J. L. \& Wiley, D. C. (1987) Structure of the human class I histocompatibility antigen, HLA-A2, Nature. 329, 506-12.

2. Hafstrand, I., Doorduijn, E. M., Duru, A. D., Buratto, J., Oliveira, C. C., Sandalova, T., van Hall, T. \& Achour, A. (2016) The MHC Class I Cancer-Associated Neoepitope Trh4 Linked with Impaired Peptide Processing Induces a Unique Noncanonical TCR Conformer, $J$ Immunol. 196, 2327-34.

3. Madhurantakam, C., Duru, A. D., Sandalova, T., Webb, J. R. \& Achour, A. (2012) Inflammation-associated nitrotyrosination affects TCR recognition through reduced stability and alteration of the molecular surface of the MHC complex, Plos One. 7, e32805.

4. Uchtenhagen, H., Abualrous, E. T., Stahl, E., Allerbring, E. B., Sluijter, M., Zacharias, M., Sandalova, T., van Hall, T., Springer, S., Nygren, P. A. \& Achour, A. (2013) Proline substitution independently enhances $\mathrm{H}-2 \mathrm{D}(\mathrm{b})$ complex stabilization and TCR recognition of melanoma-associated peptides, European journal of immunology. 43, 3051-60.

5. van Stipdonk, M. J., Badia-Martinez, D., Sluijter, M., Offringa, R., van Hall, T. \& Achour, A. (2009) Design of agonistic altered peptides for the robust induction of CTL directed towards $\mathrm{H}-2 \mathrm{Db}$ in complex with the melanoma-associated epitope gp100, Cancer research. 69, 7784-92.

6. Halabelian, L., Ricagno, S., Giorgetti, S., Santambrogio, C., Barbiroli, A., Pellegrino, S., Achour, A., Grandori, R., Marchese, L., Raimondi, S., Mangione, P. P., Esposito, G., AlShawi, R., Simons, J. P., Speck, I., Stoppini, M., Bolognesi, M. \& Bellotti, V. (2014) Class I Major Histocompatibility Complex, the Trojan Horse for Secretion of Amyloidogenic beta2-Microglobulin, The Journal of biological chemistry. 289, 3318-27.

7. Floege, J. \& Ehlerding, G. (1996) Beta-2-microglobulin-associated amyloidosis, Nephron. 72, 9-26.

8. Valleix, S., Gillmore, J. D., Bridoux, F., Mangione, P. P., Dogan, A., Nedelec, B., Boimard, M., Touchard, G., Goujon, J. M., Lacombe, C., Lozeron, P., Adams, D., Lacroix, C.,

This article is protected by copyright. All rights reserved. 
Maisonobe, T., Plante-Bordeneuve, V., Vrana, J. A., Theis, J. D., Giorgetti, S., Porcari, R., Ricagno, S., Bolognesi, M., Stoppini, M., Delpech, M., Pepys, M. B., Hawkins, P. N. \& Bellotti, V. (2012) Hereditary systemic amyloidosis due to Asp76Asn variant beta2microglobulin, $N$ Engl J Med. 366, 2276-83.

9. Gejyo, F., Yamada, T., Odani, S., Nakagawa, Y., Arakawa, M., Kunitomo, T., Kataoka, H., Suzuki, M., Hirasawa, Y., Shirahama, T., Cohen, A. S. \& Schimd, K. (1985) A new form of amyloid protein associated with chronic hemodialysis was identified as beta 2microglobulin, Biochemical and biophysical research communications. 129, 701-6.

10. Niwa, T. (1997) Beta2-Microglobulin dialysis amyloid and its formation: role of 3deoxyglucosone and advanced glycation end products, Nephron. 76, 373-91.

11. Ivanova, M. I., Sawaya, M. R., Gingery, M., Attinger, A. \& Eisenberg, D. (2004) An amyloid-forming segment of beta2-microglobulin suggests a molecular model for the fibril, Proceedings of the National Academy of Sciences of the United States of America. 101, 10584-9.

12. Zhang, P., Fu, X., Sawashita, J., Yao, J., Zhang, B., Qian, J., Tomozawa, H., Mori, M., Ando, Y., Naiki, H. \& Higuchi, K. (2010) Mouse model to study human A beta2M amyloidosis: generation of a transgenic mouse with excessive expression of human beta2-microglobulin, Amyloid : the international journal of experimental and clinical investigation : the official journal of the International Society of Amyloidosis. 17, 50-62.

13. Pashley, C. L., Hewitt, E. W. \& Radford, S. E. (2016) Comparison of the aggregation of homologous beta2-microglobulin variants reveals protein solubility as a key determinant of amyloid formation, Journal of molecular biology. 428, 631-643.

14. Eichner, T., Kalverda, A. P., Thompson, G. S., Homans, S. W. \& Radford, S. E. (2011) Conformational conversion during amyloid formation at atomic resolution, Molecular cell. 41, 161-72.

15. Karamanos, T. K., Kalverda, A. P., Thompson, G. S. \& Radford, S. E. (2014) Visualization of transient protein-protein interactions that promote or inhibit amyloid assembly, Molecular cell. 55, 214-26.

16. de Rosa, M., Barbiroli, A., Giorgetti, S., Mangione, P. P., Bolognesi, M. \& Ricagno, S. (2015) Decoding the Structural Bases of D76N ss2-Microglobulin High Amyloidogenicity through Crystallography and Asn-Scan Mutagenesis, Plos One. 10, e0144061.

17. Ricagno, S., Raimondi, S., Giorgetti, S., Bellotti, V. \& Bolognesi, M. (2009) Human beta-2 microglobulin W60V mutant structure: Implications for stability and amyloid aggregation, Biochemical and biophysical research communications. 380, 543-7.

18. Camilloni, C., Sala, B. M., Sormanni, P., Porcari, R., Corazza, A., De Rosa, M., Zanini, S., Barbiroli, A., Esposito, G., Bolognesi, M., Bellotti, V., Vendruscolo, M. \& Ricagno, S. (2016) Rational design of mutations that change the aggregation rate of a protein while maintaining its native structure and stability, Scientific reports. 6, 25559.

19. Platt, G. W., Routledge, K. E., Homans, S. W. \& Radford, S. E. (2008) Fibril growth kinetics reveal a region of beta2-microglobulin important for nucleation and elongation of aggregation, Journal of molecular biology. 378, 251-63.

20. Le Marchand, T., de Rosa, M., Salvi, N., Sala, B. M., Andreas, L. B., Barbet-Massin, E., Sormanni, P., Barbiroli, A., Porcari, R., Sousa Mota, C., de Sanctis, D., Bolognesi, M., Emsley, L., Bellotti, V., Blackledge, M., Camilloni, C., Pintacuda, G. \& Ricagno, S. (2018) Conformational dynamics in crystals reveal the molecular bases for D76N beta-2 microglobulin aggregation propensity, Nature communications. 9, 1658.

21. Esposito, G., Ricagno, S., Corazza, A., Rennella, E., Gumral, D., Mimmi, M. C., Betto, E., Pucillo, C. E., Fogolari, F., Viglino, P., Raimondi, S., Giorgetti, S., Bolognesi, B., Merlini, G.,

This article is protected by copyright. All rights reserved. 
Stoppini, M., Bolognesi, M. \& Bellotti, V. (2008) The controlling roles of Trp60 and Trp95 in beta2-microglobulin function, folding and amyloid aggregation properties, Journal of molecular biology. 378, 885-95.

22. Sormanni, P., Aprile, F. A. \& Vendruscolo, M. (2015) The CamSol method of rational design of protein mutants with enhanced solubility, Journal of molecular biology. 427, 478-90.

23. Santambrogio, C., Ricagno, S., Colombo, M., Barbiroli, A., Bonomi, F., Bellotti, V., Bolognesi, M. \& Grandori, R. (2010) DE-loop mutations affect beta2 microglobulin stability, oligomerization, and the low-pH unfolded form, Protein Sci. 19, 1386-94.

24. Achour, A., Harris, R. A., Persson, K., Sundback, J., Sentman, C. L., Schneider, G., Lindqvist, Y. \& Karre, K. (1999) Murine class I major histocompatibility complex H-2Dd: expression, refolding and crystallization, Acta crystallographica. 55, 260-2.

25. Achour, A., Michaelsson, J., Harris, R. A., Ljunggren, H. G., Karre, K., Schneider, G. \& Sandalova, T. (2006) Structural basis of the differential stability and receptor specificity of $\mathrm{H}-2 \mathrm{Db}$ in complex with murine versus human beta2-microglobulin, Journal of molecular biology. 356, 382-96.

26. Iwata, K., Fujiwara, T., Matsuki, Y., Akutsu, H., Takahashi, S., Naiki, H. \& Goto, Y. (2006) 3D structure of amyloid protofilaments of beta2-microglobulin fragment probed by solid-state NMR, Proceedings of the National Academy of Sciences of the United States of America. 103, 18119-24.

27. Iwata, K., Matsuura, T., Sakurai, K., Nakagawa, A. \& Goto, Y. (2007) High-resolution crystal structure of beta2-microglobulin formed at pH 7.0, Journal of biochemistry. 142, 413-9.

28. Ricagno, S., Colombo, M., de Rosa, M., Sangiovanni, E., Giorgetti, S., Raimondi, S., Bellotti, V. \& Bolognesi, M. (2008) DE loop mutations affect beta-2 microglobulin stability and amyloid aggregation, Biochemical and biophysical research communications. 377, 146-50.

29. Chiti, F., De Lorenzi, E., Grossi, S., Mangione, P., Giorgetti, S., Caccialanza, G., Dobson, C. M., Merlini, G., Ramponi, G. \& Bellotti, V. (2001) A partially structured species of beta 2-microglobulin is significantly populated under physiological conditions and involved in fibrillogenesis, The Journal of biological chemistry. 276, 46714-21.

30. Halabelian, L., Relini, A., Barbiroli, A., Penco, A., Bolognesi, M. \& Ricagno, S. (2015) A covalent homodimer probing early oligomers along amyloid aggregation, Scientific reports. 5, 14651.

31. Ami, D., Ricagno, S., Bolognesi, M., Bellotti, V., Doglia, S. M. \& Natalello, A. (2012) Structure, stability, and aggregation of beta- 2 microglobulin mutants: insights from a Fourier transform infrared study in solution and in the crystalline state, Biophys J. 102, 1676-84.

32. Colombo, M., de Rosa, M., Bellotti, V., Ricagno, S. \& Bolognesi, M. (2012) A recurrent D-strand association interface is observed in beta-2 microglobulin oligomers, FEBS J. 279, 1131-43.

33. Rennella, E., Cutuil, T., Schanda, P., Ayala, I., Gabel, F., Forge, V., Corazza, A., Esposito, G. \& Brutscher, B. (2013) Oligomeric states along the folding pathways of beta2microglobulin: kinetics, thermodynamics, and structure, Journal of molecular biology. 425, 2722-36.

34. Hong, D. P., Gozu, M., Hasegawa, K., Naiki, H. \& Goto, Y. (2002) Conformation of beta 2-microglobulin amyloid fibrils analyzed by reduction of the disulfide bond, The Journal of biological chemistry. 277, 21554-60.

This article is protected by copyright. All rights reserved. 
35. Patel, J. R., Xu, Y., Capitini, C., Chiti, F. \& De Simone, A. (2018) Backbone NMR assignments of HypF-N under conditions generating toxic and non-toxic oligomers, Biomolecular NMR assignments. 12, 273-277.

36. Beerbaum, M., Ballaschk, M., Erdmann, N., Schnick, C., Diehl, A., Uchanska-Ziegler, B., Ziegler, A. \& Schmieder, P. (2013) NMR spectroscopy reveals unexpected structural variation at the protein-protein interface in MHC class I molecules, Journal of biomolecular NMR. 57, 167-78.

37. Bonomi, M., Camilloni, C. \& Vendruscolo, M. (2016) Metadynamic metainference: Enhanced sampling of the metainference ensemble using metadynamics, Scientific reports. 6, 31232 .

38. Gates, F. T., 3rd, Coligan, J. E. \& Kindt, T. J. (1981) Complete amino acid sequence of murine beta 2-microglobulin: structural evidence for strain-related polymorphism, Proceedings of the National Academy of Sciences of the United States of America. 78, 5548.

39. Hermel, E., Robinson, P. J., She, J. X. \& Lindahl, K. F. (1993) Sequence divergence of B2m alleles of wild Mus musculus and Mus spretus implies positive selection, Immunogenetics. 38, 106-16.

40. Merlini, G. \& Bellotti, V. (2003) Molecular mechanisms of amyloidosis, N Engl J Med. 349, 583-96.

41. Chiti, F., Mangione, P., Andreola, A., Giorgetti, S., Stefani, M., Dobson, C. M., Bellotti, V. \& Taddei, N. (2001) Detection of two partially structured species in the folding process of the amyloidogenic protein beta 2-microglobulin, Journal of molecular biology. 307, 379-91.

42. Neudecker, P., Robustelli, P., Cavalli, A., Walsh, P., Lundstrom, P., Zarrine-Afsar, A., Sharpe, S., Vendruscolo, M. \& Kay, L. E. (2012) Structure of an intermediate state in protein folding and aggregation, Science (New York, NY. 336, 362-6.

43. Esposito, G., Michelutti, R., Verdone, G., Viglino, P., Hernandez, H., Robinson, C. V., Amoresano, A., Dal Piaz, F., Monti, M., Pucci, P., Mangione, P., Stoppini, M., Merlini, G., Ferri, G. \& Bellotti, V. (2000) Removal of the N-terminal hexapeptide from human beta2microglobulin facilitates protein aggregation and fibril formation, Protein Sci. 9, 831-45. 44. Yamamoto, S., Yamaguchi, I., Hasegawa, K., Tsutsumi, S., Goto, Y., Gejyo, F. \& Naiki, H. (2004) Glycosaminoglycans enhance the trifluoroethanol-induced extension of beta 2microglobulin-related amyloid fibrils at a neutral pH, J Am Soc Nephrol. 15, 126-33.

45. Naiki, H., Haschimoto, N., Suzuki, S., Rimura, H., Nakakuki, K. \& Gejyo, F. (1997) Establishment of a kinetic model of dialysis-related amyloid fibril extension in vitro., AMYLOID: Int Exp Clin Invest. 4, 223-32.

46. Otwinowski, Z. (1993) Oscillation Data Reduction Program, Daresbury Laboratory, Warrington, United Kingdom.

47. Navaza, J. (2001) Implementation of molecular replacement in AMoRe, Acta crystallographica. 57, 1367-72.

48. Brunger, A. T., Adams, P. D., Clore, G. M., DeLano, W. L., Gros, P., Grosse-Kunstleve, R. W., Jiang, J. S., Kuszewski, J., Nilges, M., Pannu, N. S., Read, R. J., Rice, L. M., Simonson, T. \& Warren, G. L. (1998) Crystallography \& NMR system: A new software suite for macromolecular structure determination, Acta crystallographica. 54, 905-21.

49. Murshudov, G. N., Vagin, A. A. \& Dodson, E. J. (1997) Refinement of macromolecular structures by the maximum-likelihood method, Acta crystallographica. 53, 240-55.

50. Delaglio, F., Grzesiek, S., Vuister, G. W., Zhu, G., Pfeifer, J. \& Bax, A. (1995) NMRPipe: a multidimensional spectral processing system based on UNIX pipes, Journal of biomolecular NMR. 6, 277-93.

This article is protected by copyright. All rights reserved. 
51. Lee, W., Tonelli, M. \& Markley, J. L. (2015) NMRFAM-SPARKY: enhanced software for biomolecular NMR spectroscopy, Bioinformatics. 31, 1325-7.

52. Jung, Y. S. \& Zweckstetter, M. (2004) Mars -- robust automatic backbone assignment of proteins, Journal of biomolecular NMR. 30, 11-23.

53. Abraham, M. J., Murtola, T., Schulz, R., Pall, S., Smith, J. C., Hess, B. \& Lindhal, E. (2015) GROMACS: High performance molecular simulations through multi-level parallelism from laptops to supercomputers. , SoftwareX. 1-2, 19-25.

54. Tribello, G. A., Bonomi, F., Branduardi, D., Camilloni, C. \& Bussi, G. (2014) PLUMED 2: New feathers for an old bird, Computer Physics Communications. 182, 604-13.

55. Bonomi, M. \& Camilloni, C. (2017) Integrative structural and dynamical biology with PLUMED-ISDB, Bioinformatics. 33, 3999-4000.

56. Best, R. B. \& Mittal, J. (2010) Protein simulations with an optimized water model: cooperative helix formation and temperature-induced unfolded state collapse, The journal of physical chemistry B. 114, 14916-23.

57. Abascal, J. L. \& Vega, C. (2005) A general purpose model for the condensed phases of water: TIP4P/2005, The Journal of chemical physics. 123, 234505.

58. Bonomi, M., Camilloni, C., Cavalli, A. \& Vendruscolo, M. (2016) Metainference: A Bayesian inference method for heterogeneous systems, Science advances. 2, e1501177.

59. Lohr, T., Jussupow, A. \& Camilloni, C. (2017) Metadynamic metainference: Convergence towards force field independent structural ensembles of a disordered peptide, The Journal of chemical physics. 146, 165102.

60. Pfaendtner, J. \& Bonomi, M. (2015) Efficient Sampling of High-Dimensional FreeEnergy Landscapes with Parallel Bias Metadynamics, Journal of chemical theory and computation. 11, 5062-7.

61. Branduardi, D., Bussi, G. \& Parrinello, M. (2012) Metadynamics with Adaptive Gaussians, Journal of chemical theory and computation. 8, 2247-54.

62. Consortium, T. P. (2019) The PLUMED consortium: A community effort to promote openness, transparency and reproducibility in molecular simulations, Submitted.

63. Camilloni, C. \& Vendruscolo, M. (2014) Statistical mechanics of the denatured state of a protein using replica-averaged metadynamics, Journal of the American Chemical Society. 136, 8982-91.

This article is protected by copyright. All rights reserved. 
Table 1. Data collection and refinement statistics for the structure of $\mathrm{m} \beta 2 \mathrm{~m}$

PDB code

Space group

Cell $a, b, c(\AA)$

Resolution $(\AA)$

Number of unique reflections

Completeness (\%)

Redundancy

$\mathrm{I} / \sigma$

Rsym (\%)

\section{Refinement statistics}

Resolution $(\AA)$

$\mathrm{R}$ work $(\%)$

$\mathrm{R}$ free $(\%)$

Number of atoms

All

Protein

Water

Ligand

Mean isotropic B-factor $\left(\AA^{2}\right)$

Protein main-chain atoms

Protein side chain atoms

Water

Rmsd from ideal values

Bond length $(\AA)$

Bond angles $\left({ }^{\circ}\right)$

Ramachandran plot statistics

Residues in preferred regions (\%)

Residues in allowed regions (\%)

Outliers (\%)
$6 \mathrm{I} 8 \mathrm{C}$

$\mathrm{P} 2{ }_{1} 2_{1} 2_{1}$

$\begin{array}{lll}36.24 & 47.60 \quad 64.94\end{array}$

38-1.92 (1.95-1.92)

$8882(572)$

$98.6(96.8)$

$4.4(4.3)$

$20.1(7.3)$

$4.4(13.2)$

28.85-1.92

18.32

22.20

934

842

87

5

20.46

24.20

32.10

0.007

1.152

98.97

1.03

0

This article is protected by copyright. All rights reserved. 
Acknowledgments: C.C. acknowledges the CINECA award under the ISCRA initiative, for the availability of high-performance computing resources and support. We are grateful for access to synchrotron radiation at beam line BL711 at the MAX laboratory, Lund University, Sweden. Funding was provided by Fondazione Cariplo (grant n. 2016-0489) and Fondazione ARISLA (project TDP-43STRUCT) to S.R. This Work partly supported by grants from Fondazione Telethon (contract GGP17036 2017). PS is supported by a Borysiewicz Fellowship from the University of Cambridge.

Author Contributions: A.A., L.B., X.H., R.S., C.S., J.B., C.V., A.B., C.M.G.D.L., P.S., F.M., A.D.S., T.S., and C.C. performed the experiments; A.A., R.G., C.C. and S.R. designed the study; A.A., R.G., C.C. and S.R. wrote the paper with contributions from all other authors.

Conflict of interest: The authors declare that they have no conflicts of interest with the contents of this article.

This article is protected by copyright. All rights reserved. 

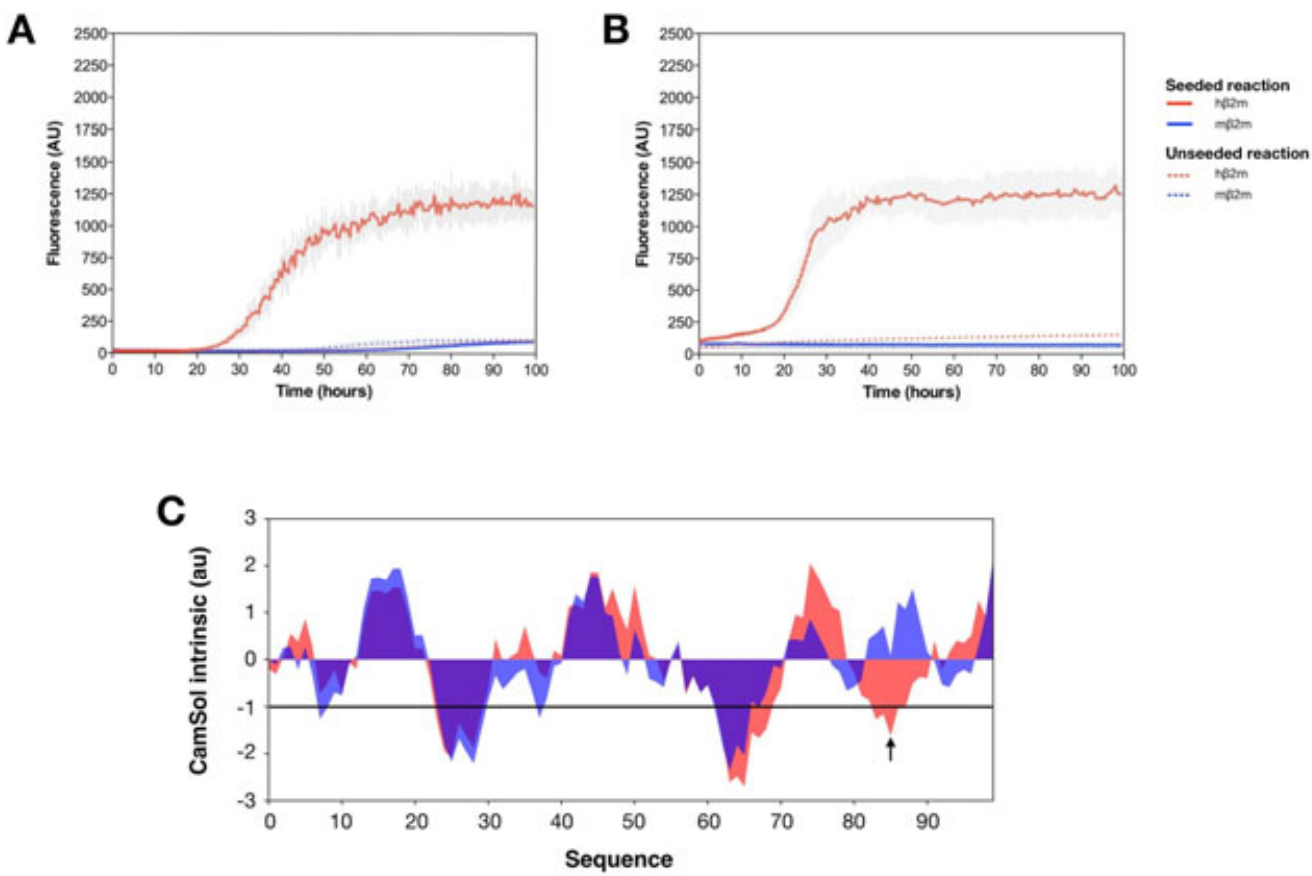

Figure 1. (A, B) The kinetics of fibril formation were monitored by fluorescence using the ThT binding assay. Monomeric $\mathrm{m} \beta 2 \mathrm{~m}$ (blue) and $\mathrm{h} \beta 2 \mathrm{~m}$ (red) were incubated at $37{ }^{\circ} \mathrm{C}$ under two different aggregation conditions at $\mathrm{pH} 7.4(\mathrm{~A})$ and at $\mathrm{pH} 2.5$ (B).

(C) CamSol intrinsic solubility scores of $\mathrm{h} \beta 2 \mathrm{~m}$ (red) and $\mathrm{m} \beta 2 \mathrm{~m}$ (blue). A score greater than 1 indicates highly soluble sites while a score lower than -1 indicates aggregation-prone sites. The two profiles reveal that in contrast to $\mathrm{m} \beta 2 \mathrm{~m}$, the regions corresponding to residues 60-70 and 80-90 in $\mathrm{h} \beta 2 \mathrm{~m}$ are prone to aggregation. The black arrow indicates the position of residue 85 .

This article is protected by copyright. All rights reserved. 

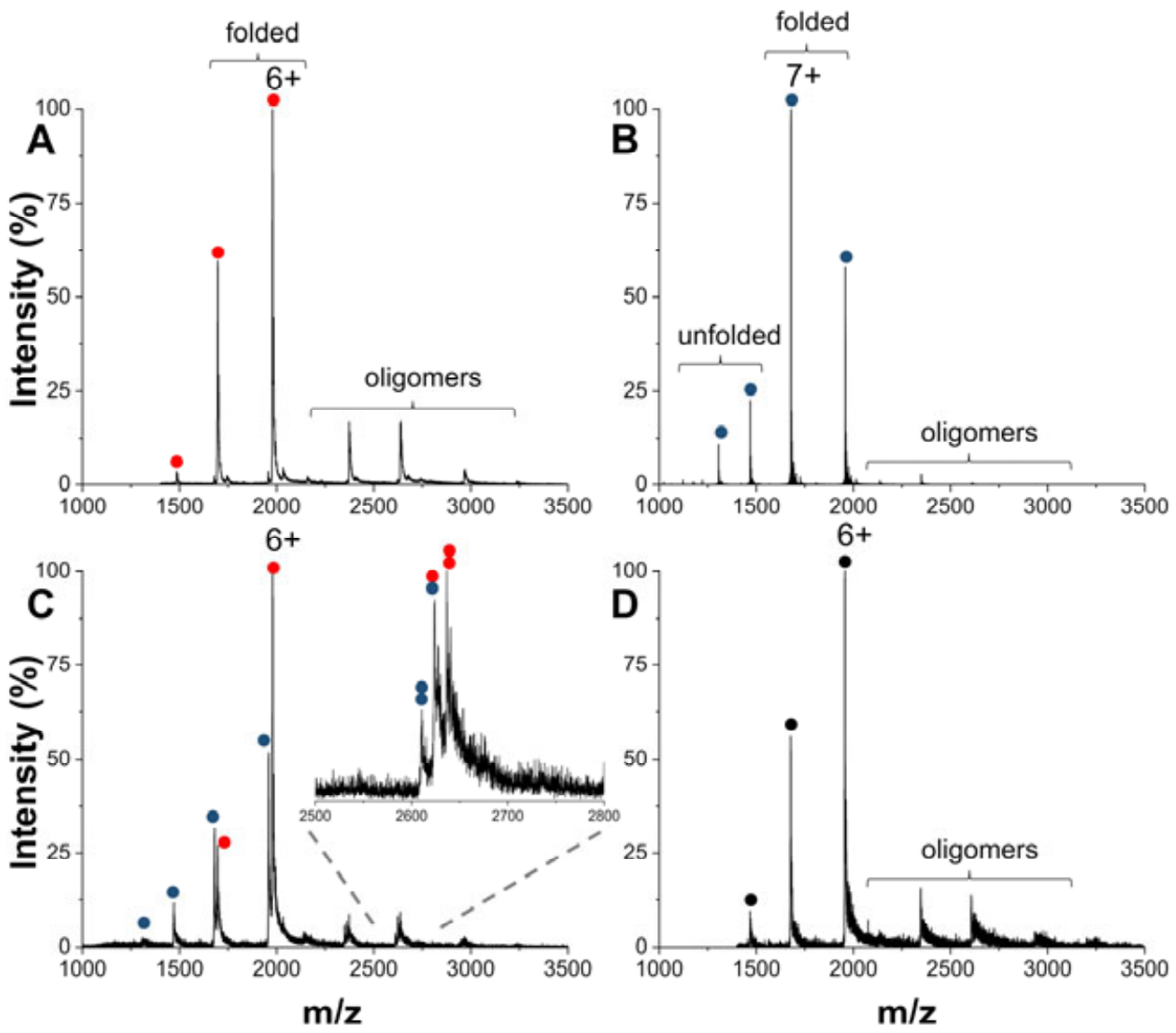

Figure 2. (A) ESI-MS spectra of $75 \mu \mathrm{M} \mathrm{h} \beta 2 \mathrm{~m}$; (B) $75 \mu \mathrm{M} \mathrm{m} \beta 2 \mathrm{~m}$; (C) a mix of $75 \mu \mathrm{M} \mathrm{h} \beta 2 \mathrm{~m}$ and 75 $\mu \mathrm{M} \mathrm{m} \beta 2 \mathrm{~m}$; (D) $75 \mu \mathrm{M}$ V85 $\mathrm{m} \beta 2 \mathrm{~m}$. The most intense peak in each panel is labeled by the corresponding charge state. In (A), (B) and (D), the peaks corresponding to distinct species are grouped by braces. The inset of panel $\mathrm{C}$ is a magnification of the 9+ signals of the dimer. Red, blue and black circles correspond to the subunits of $h \beta 2 \mathrm{~m}, \mathrm{~m} \beta 2 \mathrm{~m}$ and $\mathrm{V} 85 \mathrm{~m} \beta 2 \mathrm{~m}$, respectively.

This article is protected by copyright. All rights reserved. 

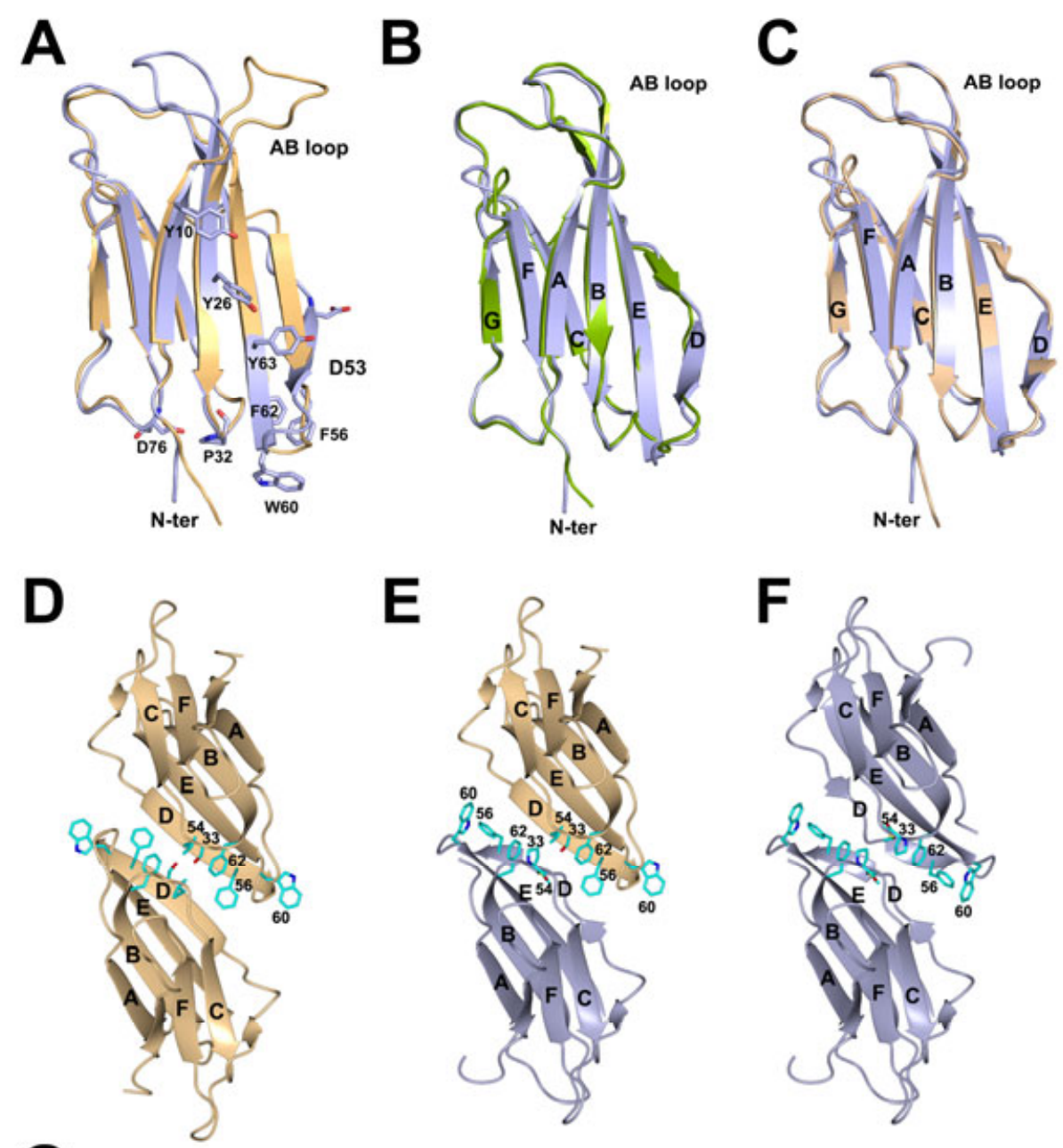

G

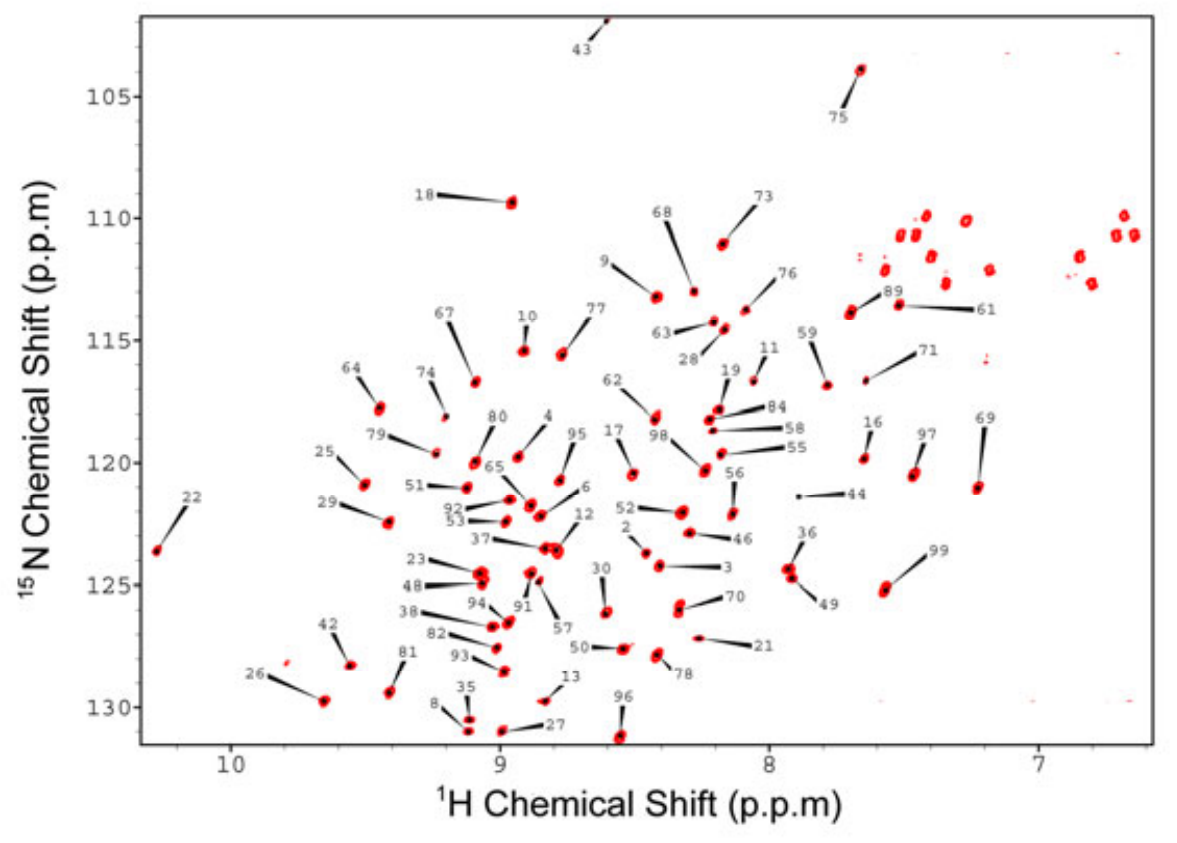

This article is protected by copyright. All rights reserved. 
Figure 3. (A-C) Comparisons of the crystal structures of the $\mathrm{m} \beta 2 \mathrm{~m}$ in purple with $\mathrm{A}$ ) the structure of monomeric $\mathrm{h} \beta 2 \mathrm{~m}$ in orange ( $\mathrm{pdb}$ code: $1 \mathrm{LDS}$ ); B) the structure of $\mathrm{m} \beta 2 \mathrm{~m}$ from an MHC I complex in green (pdb code: $1 \mathrm{BII}$ ); C) the structure of $\mathrm{h} \beta 2 \mathrm{~m}$ from a complex with mouse MHC I, H-2Dd in beige (pdb code 2F74). (D-F) Models of DD dimers built using the structures of D) two monomeric $\mathrm{h} \beta 2 \mathrm{~m}$; E) one $\mathrm{m} \beta 2 \mathrm{~m}$ and $\mathrm{h} \beta 2 \mathrm{~m}$; F) two monomeric $\mathrm{m} \beta 2 \mathrm{~m}$. Main residues involved in the interface as reported in [32] are shown. These models suggest that $\mathrm{m} \beta 2 \mathrm{~m}$ and $\mathrm{h} \beta 2 \mathrm{~m}$ structures are compatible with the formation of homo and hetero DD dimers. (G) NMR HSQC spectrum of $\mathrm{m} \beta 2 \mathrm{~m}$ at 25 " C, peaks are well resolved and 78 out 100 can be uniquely assigned.

This article is protected by copyright. All rights reserved. 
A

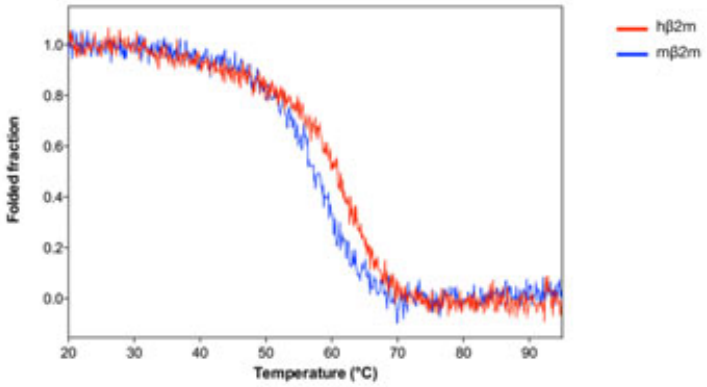

B
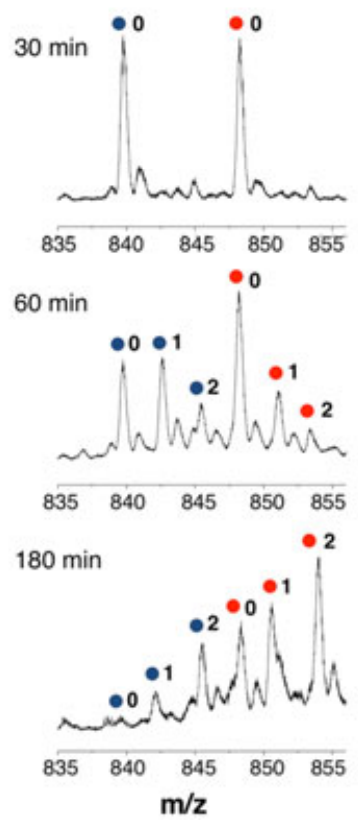

Figure 4. (A) Thermal unfolding of $8.5 \mu \mathrm{M} \mathrm{m} \beta 2 \mathrm{~m}$ and $\mathrm{h} \beta 2 \mathrm{~m}$ in $50 \mathrm{mM}$ sodium phosphate $\mathrm{pH} 7.4$ monitored by far-UV CD at $202 \mathrm{~nm}$. (B) Kinetics of disulphide bridge reduction. Magnification of the $14+$ peaks of nano-ESI-MS spectra obtained from equimolar $(25 \mu \mathrm{M})$ mixtures of $\mathrm{h} \beta 2 \mathrm{~m}$ (red circle) and $\mathrm{m} \beta 2 \mathrm{~m}$ (blue circle), incubated in $100 \mathrm{mM}$ DTT for 30, 60 or $180 \mathrm{~min}$, and alkylated by allyl bromide. Peaks are labeled according to the number of the incorporated propyl groups.

This article is protected by copyright. All rights reserved. 

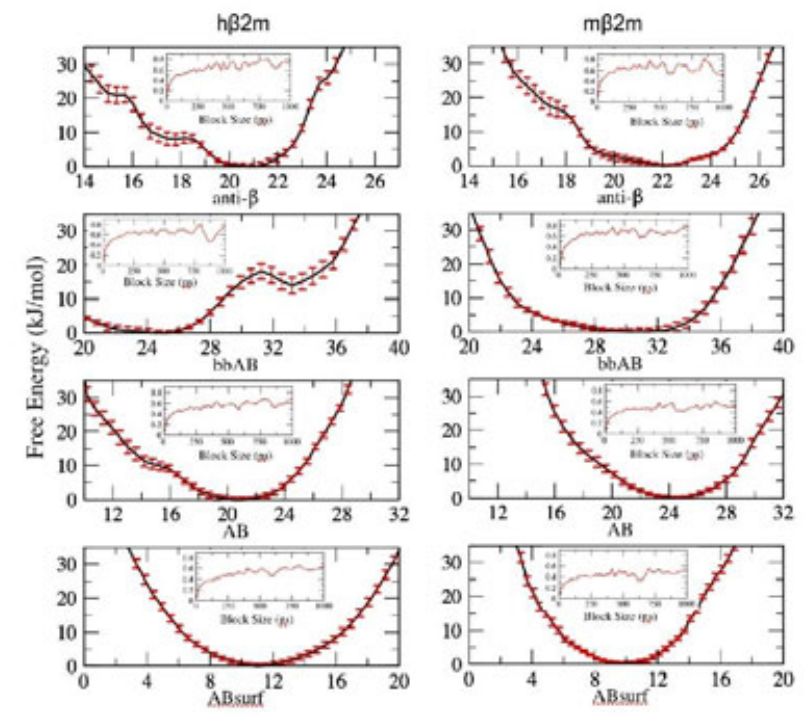

Figure 5. Free energy profiles and error estimates (inset) in $\mathrm{kJ} / \mathrm{mol}$ for the $\mathrm{h} \beta 2 \mathrm{~m}$ (left) and the $\mathrm{m} \beta 2 \mathrm{~m}$ ensembles, respectively. The free energy profiles are plotted as a function of the four biased collective variables (see Materials and Methods). The corresponding error estimates are obtained by block analysis and plotted as a function of the block size, that is the extent in ns of the time window employed for the calculation (see Materials and Methods).

This article is protected by copyright. All rights reserved. 


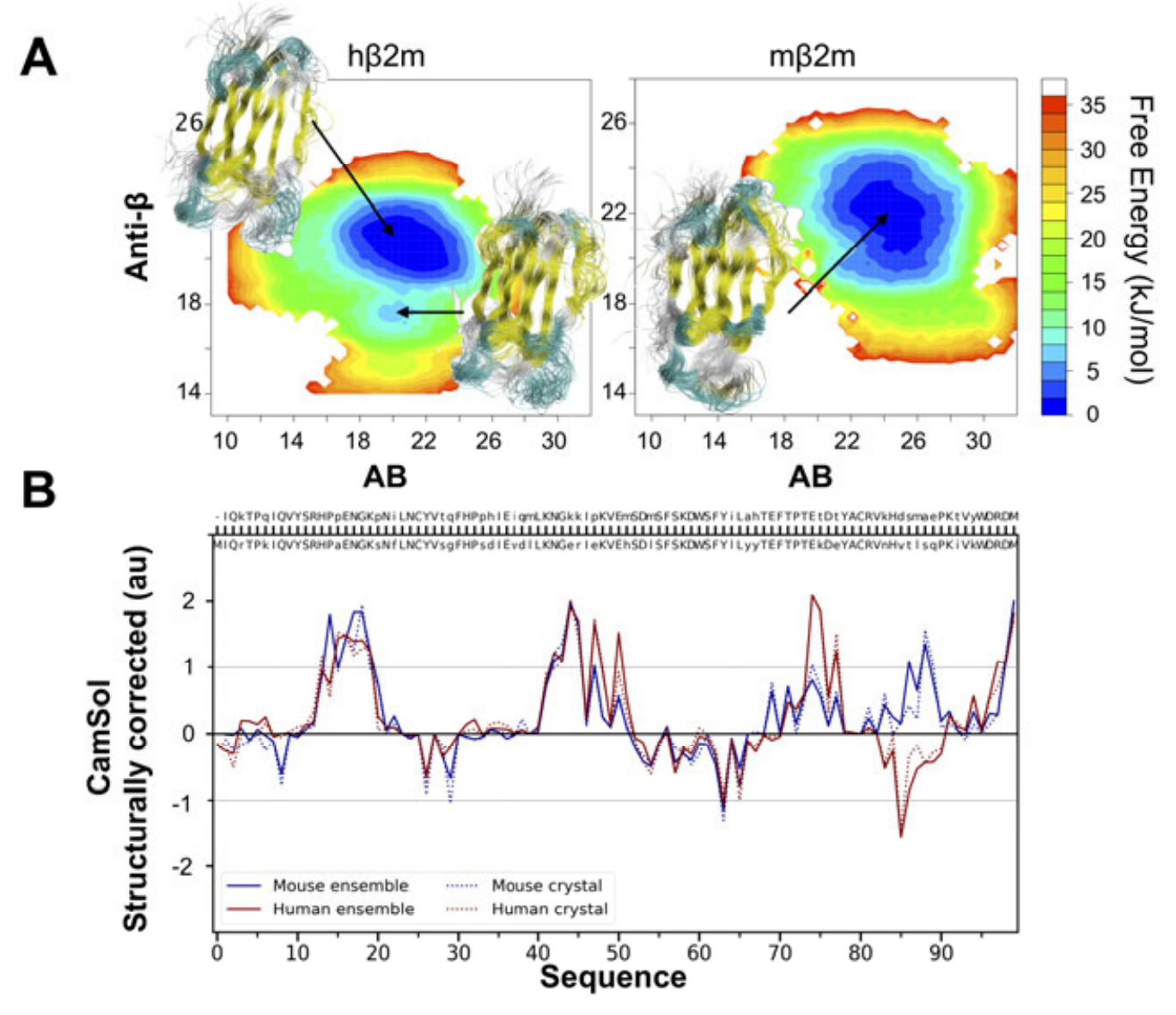

Figure 6. (A, B) Free energy surfaces for $\mathrm{h} \beta 2 \mathrm{~m}$ and $\mathrm{m} \beta 2 \mathrm{~m}$, respectively. The surfaces are shown as a function of the side chain rotameric state, $\mathrm{AB}$, and the antiparallel $\beta$-structure content (anti- $\beta$ ). (C) CamSol structurally corrected solubility scores for the $\mathrm{h} \beta 2 \mathrm{~m}$ (red solid) and $\mathrm{m} \beta 2 \mathrm{~m}$ (blue solid) conformational ensembles as well as for the $\mathrm{h} \beta 2 \mathrm{~m}$ and $\mathrm{m} \beta 2 \mathrm{~m}$ crystal structures (red dotted and blue dotted, respectively). A score greater than 1 indicates a highly soluble site while a score lower than -1 indicates an aggregation-prone site. 

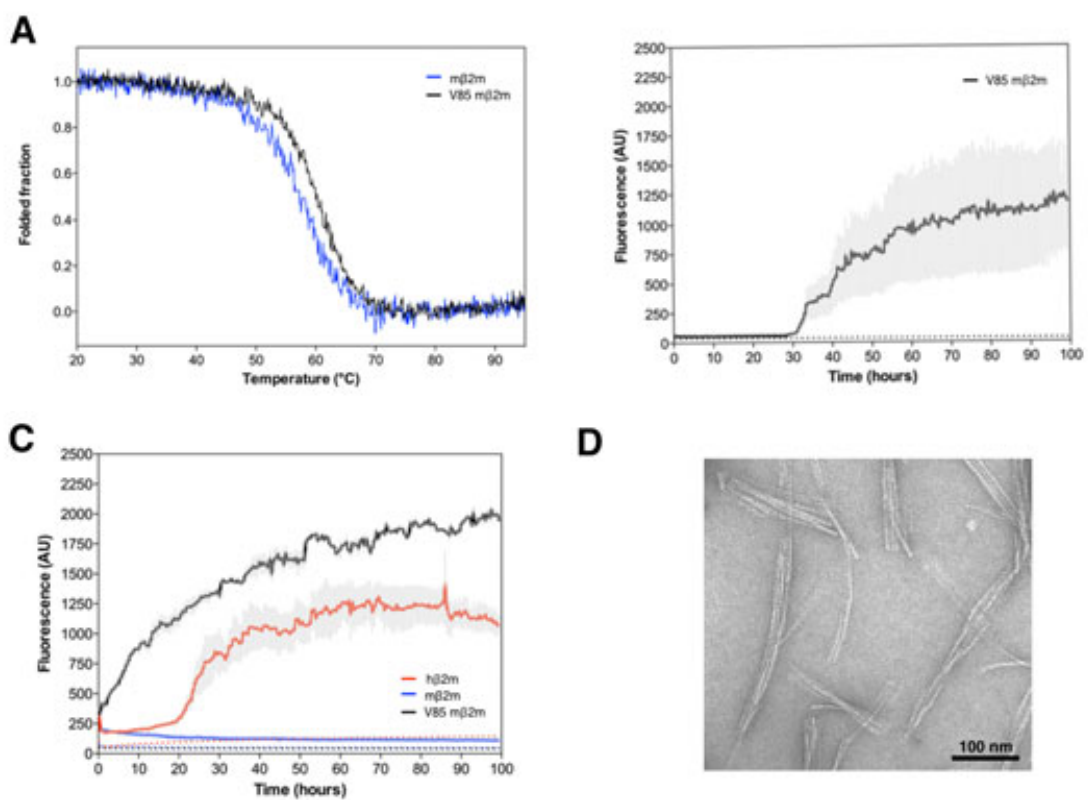

D

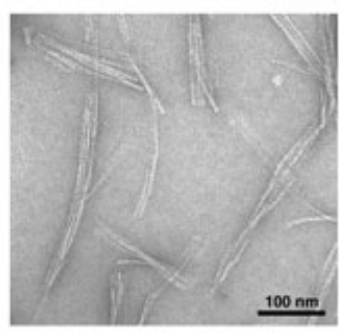

Figure 7. (A) Thermal unfolding of $8.5 \mu \mathrm{M} \mathrm{m} \beta 2 \mathrm{~m}$ and $\mathrm{V} 85 \mathrm{~m} \beta 2 \mathrm{~m}$ in $50 \mathrm{mM}$ sodium phosphate $\mathrm{pH}$ 7.4 monitored by far-UV CD at $202 \mathrm{~nm}$. (B, C) Kinetics of fibril formation monitored by fluorescence in the ThT binding assay. The V85 $\mathrm{m} \beta 2 \mathrm{~m}$ was incubated at $\mathrm{pH} 2.5$ in the presence of preformed $\mathrm{h} \beta 2 \mathrm{~m}$ seeds (B); $h \beta 2 \mathrm{~m}, \mathrm{~m} \beta 2 \mathrm{~m}$ and V85 $\mathrm{m} \beta 2 \mathrm{~m}$ were incubated in the presence of preformed V85 $\mathrm{m} \beta 2 \mathrm{~m}$ seeds at $\mathrm{pH}$ 2.5. Seeded and unseeded reactions are shown in solid and dashed lines, respectively. (D) Transmission electron microscopy micrograph shows fibrillar aggregates of the V85 m $\beta 2 \mathrm{~m}$ variant.

This article is protected by copyright. All rights reserved. 